\title{
Cognitive Impairments in Early-Detoxified Alcohol-Dependent Inpatients and Their Associations with Socio-Demographic, Clinical and Psychological Factors: An Exploratory Study
}

This article was published in the following Dove Press journal:

Neuropsychiatric Disease and Treatment

\author{
Stefano Caneva' \\ Marcella Ottonello (D) \\ Elisa Torselli (D) ${ }^{1,2}$ \\ Caterina Pistarini ${ }^{3}$ \\ Paola Spigno' \\ Elena Fiabane (iD) ${ }^{1,4}$ \\ 'Department of Physical and \\ Rehabilitation Medicine, ICS Maugeri Spa \\ $\mathrm{SB}$, Institute of Genoa Nervi, Genoa, \\ Italy; ${ }^{2}$ Miller Institute for Behavioral and \\ Cognitive Therapy, Genoa, Italy; \\ ${ }^{3}$ Department of Physical and \\ Rehabilitation Medicine, ICS Maugeri Spa \\ SB, Scientific Institute of Pavia, Genoa, \\ Italy; ${ }^{4}$ Department of Brain and \\ Behavioral Sciences, University of Pavia, \\ Pavia, Italy
}

Purpose: Cognitive impairment is common among patients with alcohol use disorder (AUD). However, neuropsychological assessment is not usually included as routine practice in alcohol rehabilitation programs. The aim of this study was to describe qualitatively the cognitive deficits in early-detoxified AUD patients undergoing rehabilitation and to explore relevant associations with socio-demographic, clinical and psychological factors.

Patients and Methods: Forty-one patients with a diagnosis of AUD were consecutively recruited from a residential rehabilitation hospital in Northern Italy. Cognitive impairment was assessed using the Brief Neuropsychological Examination 2 (ENB-2). Anxiety, depression and severity of alcohol dependence were also evaluated using validated self-report questionnaires. Alcohol relapse was investigated 1 month after discharge.

Results: Overall, $31.7 \%$ of AUD patients showed cognitive impairments according to the global score scale. However, $70.7 \%$ had an impaired performance on at least one test of the ENB-2, with particular regard to executive function, visuospatial and memory domains. Age, education and abstinence at admission were the most relevant factors associated with cognitive deficits in this clinical population.

Conclusion: The detection of cognitive impairments is essential in order to adapt alcohol rehabilitation treatment to patients with cognitive deficits and enhance clinical outcomes.

Keywords: neuropsychological functioning, alcohol use disorder, alcohol detoxification, rehabilitation, relapse

\section{Introduction}

Excessive alcohol consumption is a major public health issue worldwide: it is responsible for $5.9 \%$ of all deaths, and $5.1 \%$ of the global burden of disease and injury is attributable to alcohol. ${ }^{1}$ Alcohol use disorder (AUD) is diagnosed as mild, moderate or severe on the basis of the Diagnostic and Statistical Manual of Mental Disorders, Fifth Edition (DSM-5) criteria that are met. ${ }^{2}$

Heavy alcohol consumption is associated with an increased risk of developing substance dependence, mental and health problems (liver cirrhosis, cancers and cardiovascular diseases, among others) as well as suicidal ideation and suicide attempts in individuals with AUD. ${ }^{3,4}$ Alcohol use affects not only the drinker, but also their family and the social context through violent behaviors, social isolation, job loss, and accidents at work and on the road. ${ }^{5-7}$
Correspondence: Caterina Pistarini Department of Physical \& Rehabilitation Medicine, ICS Maugeri Spa SB, Institute of Pavia, Via Maugeri 4, Pavia, Genoa 27I00, Italy

Tel +39010 3079|250

Fax +39010 30791269

Email caterina.pistarini@icsmaugeri.it 
Between $50 \%$ and $80 \%$ of early abstinent individuals are affected by cognitive and motor deficits, with a substantial heterogeneity in the pattern and severity of deficits. ${ }^{8,9}$ One explanation given for this phenomenon refers to the total amount of alcohol intake during a person's lifetime. ${ }^{10}$ More recent views have proposed different potential causes, such as recent alcohol consumption, length of the dependence, number of withdrawals or malnutrition. ${ }^{11-16}$ This shows a substantial lack of general agreement on this topic.

Alcohol-related anatomical brain damage refers to a reduction in brain volume, usually involving the amygdala, prefrontal cortex, cerebellum and hippocampus, and to an enlargement of ventricles and sulci. ${ }^{17-22}$ This atrophy can affect cognition, even in the absence of evidence in daily life, and some areas seem to be involved more often than others. ${ }^{23,24}$ Specifically, visuospatial abilities are often associated with chronic alcohol abuse and may be still present to some extent after long-term abstinence. ${ }^{25-28}$ Impairment of executive functions is frequently associated with AUD and this weakness could lead to impulsive decision-making experiences, such as preferring immediate reward without taking into account subsequent downsides of improper alcohol intake. ${ }^{23,29-32}$ Long-term abstinence is associated with recovery in executive functions, but evidence shows that such deficits can endure in older people. ${ }^{33-35}$ Divided attention seems to be impaired, in contrast to sustained and selective attention; concerning speed of processing, studies show inconsistent results. ${ }^{36-39}$ In addition, AUD patients consistently suffer memory deficits, also due to retrieval difficulties associated with ineffective learning strategies. ${ }^{40-43}$ It is important to assess and detect cognitive impairments in order to orient and manage treatment in alcohol-dependent patients. ${ }^{8}$ For example, it is well known that cognitive behavioral therapy (CBT) is an effective treatment, but only a few studies have paid attention to patients' neuropsychological functioning; this approach could be inappropriate or insufficient for patients with cognitive impairments since it requires preserved cognitive capacities such as episodic and procedural memories and executive functions. ${ }^{8,44,45}$ Furthermore, cognitive impairment can also influence readiness to change, active participation in group therapy, treatment compliance and outcomes. ${ }^{9}$ Unfortunately, cognitive assessment is often missed in AUD treatment since neuropsychological test batteries are costly and time-consuming. ${ }^{13}$

Some previous studies explored which factors are associated with cognitive functioning in detoxified patients with AUD. These studies suggested that factors such as age, education, duration of alcohol use, severity of alcohol use and polysubstance abuse are associated with cognitive impairment and brain recovery in alcohol dependence; however, the results are mixed and further research is needed. ${ }^{11,12,25,46-52}$ The length of abstinence also plays a keyrole, because it allows the brain volume to recover, albeit possibly influenced by a few aspects of the dependence itself. ${ }^{53,54}$ For example, in 2009, Pitel et al found that recovery of episodic memory in abstainers was correlated with drinking history. ${ }^{12}$ However, other studies did not confirm these results and it is important to continue to study cognitive deficits in AUD and the effects of abstinence on cognitive and psychological functioning to enhance treatment outcomes. ${ }^{55}$

Nevertheless, maintaining abstinence is a tough goal even in people with AUD who join a treatment program, since these cognitive deficits may interfere in the rehabilitation process. ${ }^{47}$ Relapse is a major issue and a relevant outcome in substance abuse treatment, but its relationship with cognitive deficits is not clear since inconsistent results have been found. ${ }^{9,12,56}$

The primary aim of this study was to describe qualitatively the cognitive deficits in AUD patients in the early stages of a 28-day residential rehabilitation program, using a comprehensive battery of neuropsychological tests.

The secondary aim was to explore any differences in cognitive performance in relation to the main sociodemographic (age, gender, education, work status), clinical (abstinence at admission, duration of AUD, substance use comorbidity, history of substance abuse, AUDIT score, psychiatric diagnosis) and psychological factors (anxiety, depression) of this AUD population.

\section{Patients and Methods Participants}

This study evaluated 45 inpatients consecutively recruited from a 28-day residential rehabilitation institute for alcohol addiction in Northern Italy.

Study inclusion criteria were: 1) having AUD as a primary diagnosis; and 2) understanding of the Italian language. The exclusion criteria were: 1) a history of brain damage due to other diseases (e.g. traumatic brain injury); and 2) sensory or neurological disorders (e.g. blindness or dementia, including Korsakoff syndrome).

Of 45 patients, four (8.8\%) were excluded from the study because they did not meet the inclusion criteria (two had a diagnosis of neurological disorders; two did not understand 
the Italian language). The final study sample consisted of 41 patients diagnosed with AUD according to the DSM-5. ${ }^{2}$

Patients were assessed by means of self-report questionnaires and a neuropsychological battery after 7 days of detoxification. One month after hospital discharge, participants were individually interviewed to explore abstinence or any relapse into alcohol use.

The residential rehabilitation program lasted 28 days and was characterized by a high intensity of medical and psychotherapeutic treatment, including cognitive behavioral therapy (CBT) group therapy, individual psychological therapy, physical training, health education sessions and skills training. ${ }^{57-59}$ Notably, neuropsychological training was not administered because it was not a part of the rehabilitation program. Inpatients' admission criteria for rehabilitation include the absence of severe psychiatric conditions (e.g. psychosis or suicidal ideations in the last month) or medical comorbidities (e.g. stroke) which can impede the rehabilitation program; patients must also enter treatment voluntarily with a positive motivation to change their lifestyle. These criteria were evaluated by a preliminary medical assessment and clinical interview.

This research was conducted in accordance with the Declaration of Helsinki. All patients gave their written informed consent to the study and the Regional Ethics Committee of IRCCS AOU San Martino-IST (PR 387 Reg 2018) approved the research project. All authors declared no competing interests.

\section{Measures}

All patients were first interviewed using a semi-structured interview to acquire socio-demographic and clinical information. Neuropsychological assessment was carried out by an experienced neuropsychologist according to standardized procedures. Patients were individually tested, and the full battery lasted 1 hour. Self-report questionnaires were used to assess psychological factors.

The materials used are described below.

\section{Brief Neuropsychological Examination 2 (ENB-2)}

The ENB-2 is a comprehensive neuropsychological battery created by Mondini et al and standardized for the Italian population. ${ }^{60}$ It includes 16 subtests which investigate the following cognitive domains: attention, executive functioning, perception, praxis abilities and comprehension. ${ }^{60}$

The ENB-2 battery consists of the following subtests:
- Digit span: assesses short-term memory. The examiner reads a series of increasing numbers that the participant has to recall immediately. The score is given by the longest sequence of numbers correctly recalled. Range: $0-8$.

- Immediate and delayed recall prose memory: evaluates long-term memory. The examiner reads a short story that has to be repeated by the participant immediately afterward. The examiner reads the story a second time and participant has to repeat it after a 4-minute-long distracting task - see below. Range: 0-28 for each recall.

- Interference memory - 10 and 30 seconds: the subject receives and reads aloud a card with three consonants. Immediately afterward, the card is removed and the participant is asked to count in twos from a given number for a short period of time (10 seconds for the first three cards, then 30 seconds for the last three). The goal is to recall the string of consonants on the card. This procedure is repeated for each card. The score is given by each consonant correctly remembered and reported in the correct position. This test evaluates memory capacity in the absence of reiteration. Range: $0-9$ for each version.

- Trail Making Test A and B (TMT A; TMT B): in the TMT A, the participant has to connect a set of 25 scattered numbers in ascending order as quickly as possible. It evaluates the selective attention and visuospatial search. In TMT B, targets are numbers and letters and the participant has to alternate between them in ascending/alphabetical order (1-A-2-B-3, etc.) as quickly as possible. It mainly evaluates selective, divided and alternated attention, and working memory. Score is in seconds. Range: 0-999.

- Token test (brief version): a five-item test to assess comprehension abilities. Range: $0-5$.

- Word phonemic fluency: as in other phonemic fluency tests, this evaluates the ability to retrieve words on the basis of the initial letter (C, P and $\mathrm{S}$ ) in 1 minute. Score is the mean of the correct words retrieved in the three conditions.

- Abstraction: the aim is to find a word to link two other words (e.g. Q: pasta and milk are ... A: food). It evaluates reasoning abilities and concept abstraction. Range: $0-6$.

- Cognitive estimation: evaluates the ability to give coherent answers to ambiguous questions (e.g. Q: How long is a guitar?). Range: $0-5$. 
- Overlapping figure: this test is performed between the two prose memory test recalls as a distracting task. The examiner gives the participant a sheet with more than 50 overlapping figures with the goal of identifying the largest number of these in 4 minutes. This test is mainly a visual recognition task. Range: $0-50$.

- Copy drawing: the participant has to copy a complex but familiar figure. Score range: $0-2$.

- Spontaneous drawing: the instructions are to draw a daisy with one leaf and the stem. Evaluates praxis abilities and the capability of accessing the visual representation of a simple figure. Range: $0-2$.

- Ideative and ideomotor praxis tests: the participant has to perform gestures with or without meaning and to replicate the examiner's gestures. Range: 0-6.

- Clock drawing: the participant has to place numbers on a printed circle as though it were a clock and then draw hands to a given hour. The examiner evaluates the presence of the correct numbers and the spatial accuracy of both numbers and hands. This is a complex task that involves executive functions and visuospatial abilities. Range: $0-10$.

The battery provides both an assessment of each cognitive task and a total score (global cognitive index) indicating the global cognitive profile. The tests were adjusted for age and education in the Italian population and normative scores were calculated. The 5th percentile was used to determine cut-off scores, according to which the performance was classified in three categories: below average (impaired), at the limit, and average (normative). The battery was previously used in addiction studies and showed good psychometric characteristics. ${ }^{60-63}$

\section{Cognitive Behavioral Assessment - Outcome Evaluation (CBA-OE)}

Depression and anxiety were assessed using two scales from the Cognitive Behavioral Assessment - Outcome Evaluation (CBA-OE) questionnaire. ${ }^{64}$ The Depression (19 items) and the Anxiety scales (14 items) were measured on a five-point Likert-type scale ranging from 1 (= nothing) to 5 (= a lot). Higher scores indicate higher levels of depression (range 19-95), with two clinical cut-off points: 32 for moderate depression and 45 for severe depression. Higher scores indicate higher levels of anxiety (range 0-56), with two clinical cut-off points: 25 for moderate anxiety and 36 for severe anxiety. Both scales have demonstrated excellent reliability in clinical groups (depression, $\alpha=0.91$; anxiety, $\alpha=0.90$ ). ${ }^{64}$

\section{Alcohol Use Disorders Identification Test (AUDIT)}

The Alcohol Use Disorders Identification Test (AUDIT) is a questionnaire developed by the World Health Organization to assess alcohol consumption, drinking behaviors and alcohol-related problems. ${ }^{65}$ It consists of 10 items and respondents are asked to choose one of five statements (per item) that most applies to their use of alcoholic beverages over the past year. Responses are scored from 0 to 4 , and the summary score for the total AUDIT ranges from 0 (absence of problem drinking behavior) to 40 (relevant levels of problem drinking behaviors and alcohol dependence).

This self-report measure has been extensively used and possesses good validity and reliability. ${ }^{65}$

\section{Statistical Analysis}

Descriptive statistics were used to analyze sociodemographic, clinical and psychological characteristics of the sample. The assumption of normality for all the psychological scales was verified. The AUDIT scale was dichotomized considering the median of the scores' distribution, to obtain two different groups characterized by high level $(\leq 33)$ or very high level $(\geq 34)$ of severity of alcohol dependence. This method has been used in previous scientific studies. ${ }^{57,66}$ One-way analysis of variance (ANOVA) was used to explore whether cognitive functions measured by the ENB-2 (both global cognitive index and performance for each test) significantly differed among the main socio-demographic, clinical and psychological factors. Finally, ANOVA was also used to explore any significant differences in cognitive functions between relapsed and abstinent patients at the 1-month follow-up. A $p$ value smaller than $0.05(p<0.05)$ was considered statistically significant. All statistical analyses were conducted using SPSS for Windows, version 19.0.

\section{Results}

Participants in this study had a mean age of $52.29( \pm 8.14)$ years. The majority of patients were males $(58.5 \%)$, with a middle to high educational level $(65.9 \%)$, and unemployed (63.4\%). Concerning clinical features, the largest part of the sample did not show a history of psychiatric disorders (53.7\%) and was not abstinent (82.1\%) at admission. The majority of the sample had a long duration $(\geq 10$ years) of AUD (56.1\%) and did not have substance use comorbidity $(80.5 \%)$, but had a previous history of 
substance use disorder other than alcohol (51.2\%). Most patients were smokers (90.2\%). Socio-demographic and clinical aspects of the sample are shown in Table 1.

Results of the neuropsychological assessment (ENB-2 battery) are described in Table 2 . We calculated mean scores and the frequency distribution (percentage) of impaired scores for each ENB-2 subtest and for the global score.

A total of $31.7 \%$ of AUD patients showed cognitive impairment measured according to the global score scale. However, only 12 people (29.3\%) in the sample performed well in every subtest, and of the remaining patients, seven (17.1\%) had a poor performance on one subtest and 22 $(53.7 \%)$ on two or more subtests (Figure 1).

With regard to the six cognitive domains (Attention, Memory, Comprehension, Executive functions, Visuospatial abilities, Praxis) we found that the majority of impaired results referred to 1) Visuospatial abilities: Copy drawing (36.6\%) and Overlapping figure test $(31.7 \%)$; 2) Executive functions: Clock drawing (29.3\%), Phonemic fluency (17.1\%) and TMT

Table I Socio-Demographic and Clinical Characteristics of the Sample $(\mathrm{N}=4 \mathrm{I})$

\begin{tabular}{|c|c|c|}
\hline Variables & & $\mathbf{N}(\%)$ \\
\hline \multirow[t]{2}{*}{ Age (years) } & $30-50$ & $18(43.9)$ \\
\hline & $\geq 51$ & $23(56.1)$ \\
\hline \multirow[t]{2}{*}{ Gender } & Male & $24(58.5)$ \\
\hline & Female & I7 (4I.5) \\
\hline \multirow[t]{2}{*}{ Education (years) } & $\leq 8$ & $14(34.1)$ \\
\hline & $\geq 9$ & $27(65.9)$ \\
\hline \multirow[t]{2}{*}{ Work status } & Employed & $15(36.6)$ \\
\hline & Unemployed & $26(63.4)$ \\
\hline \multirow[t]{2}{*}{ Psychiatric diagnosis } & Yes & $19(46.3)$ \\
\hline & No & $22(53.7)$ \\
\hline \multirow[t]{2}{*}{ Abstinence at admission } & Yes & $7(17.1)$ \\
\hline & No & 34 (82.9) \\
\hline \multirow[t]{2}{*}{ Duration of AUD (years) } & $2-9$ & 18 (43.9) \\
\hline & $\geq 10$ & $23(56.1)$ \\
\hline \multirow[t]{2}{*}{ Smoking } & Yes & $37(90.2)$ \\
\hline & No & $4(9.8)$ \\
\hline \multirow[t]{2}{*}{ Substance use comorbidity ${ }^{a}$} & Yes & $8(19.5)$ \\
\hline & No & $33(80.5)$ \\
\hline \multirow[t]{2}{*}{ Previous substance abuse } & Yes & $2 I(5 \mid .2)$ \\
\hline & No & $20(48.8)$ \\
\hline
\end{tabular}

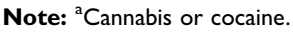

Abbreviations: $\mathrm{N}$, number; AUD, alcohol use disorder.
B (19.5\%); and 3) Memory: Memory with interference - 10 seconds $(17.1 \%)$.

Table 3 shows that the majority of the sample had clinically relevant symptoms of anxiety (57.6\%) or depression $(63.6 \%)$ and $48.5 \%$ reported both clinically relevant anxiety and depression. High levels of AUD severity were measured by the AUDIT questionnaire $(\mathrm{M}=32.25$, $\mathrm{SD}=6.77$; range 0-40). Alcohol relapse had occurred for $51.4 \%$ of the sample at 1 month after hospital discharge.

Cognitive global score was compared for the sociodemographic (age, gender, education, work status), clinical (psychiatric diagnosis, abstinence at admission, duration of AUD, substance use comorbidity, history of substance abuse, AUDIT score) and psychological (anxiety, depression) characteristics of the sample in order to explore any differences between groups.

We found that cognitive global score was significantly higher for the group with a high level of education $(\mathrm{M}=78.81$; $\mathrm{SD}=7.89)$ compared to the low-level group (67.64; $\mathrm{SD}=10.08)(F=15.26 ; p<0.001)$. In relation to clinical factors, we found a significant difference $(F=7.82 ; p<0.01)$ between abstinent patients at admission $(\mathrm{M}=84.00$; $\mathrm{SD}=6.19)$ and non-abstinent patients $(\mathrm{M}=73.14$; $\mathrm{SD}=9.81)$. No statistically significant differences were found for psychological factors (all $p>0.05$ ). Results are summarized in Figure 2.

We explored any significant differences in all cognitive domains (ENB-2 subtests) for socio-demographic, clinical and psychological factors. Only statistically significant results $(p<0.05)$ are reported in Tables 4 and 5, whereas complete results are available as supplementary materials.

In relation to socio-demographic factors, we found that: 1) females performed significantly better in Abstract reasoning (executive function) compared to males $(F=5.03 ; p=0.03) ; 2)$ younger patients performed significantly better in TMT A (attention) ( $F=3.79$; $p=0.05)$, Phonemic fluency $(\mathrm{F}=4.99 ; \quad \mathrm{p}=0.03)$ and Abstract reasoning (executive functions) ( $F=4.72$; $p=0.03$ ); and 3 ) patients with high education scored significantly higher compared to the group with low education in all Memory subtests: Prose memory - immediate recall $(F=6.75 ; p=0.01)$, Prose memory - delayed recall $(F=14.72 ; p<0.001)$, Memory with interference -10 seconds $(F=5.80 ; p=0.02)$ and Memory with interference 30 seconds $(F=7.87 ; p=0.01)$; finally, the high-level education group performed better in both Phonemic fluency (executive functions) $(F=7.13 ; p=0.01)$ and Copy drawing 
Table 2 Cognitive Functions in Early-Detoxified AUD Patients $(\mathrm{N}=4 \mathrm{I})$

\begin{tabular}{|c|c|c|c|c|}
\hline \multirow[t]{2}{*}{ Cognitive Domain } & \multirow[t]{2}{*}{ Test } & \multirow[t]{2}{*}{ Mean士SD } & \multicolumn{2}{|c|}{ Score: $\mathbf{N}(\%)$} \\
\hline & & & Impaired & Limits of Norm \\
\hline Attention & TMT A $\mathrm{A}^{\mathrm{a}}$ & $40.04 \pm 17.85$ & $4(9.8)$ & - \\
\hline Memory & $\begin{array}{l}\text { Digit span } \\
\text { Prose memory - immediate recall } \\
\text { Prose memory - delayed recall } \\
\text { Memory with interference }-10 \text { seconds } \\
\text { Memory with interference }-30 \text { seconds }\end{array}$ & $\begin{array}{l}5.6 \mid \pm 0.97 \\
|4.34 \pm 4.7| \\
\mid 8.27 \pm 5.15 \\
6.98 \pm 2.55 \\
6.59 \pm 2.44\end{array}$ & $\begin{array}{l}2(4.9) \\
2(4.9) \\
1(2.4) \\
7(17.1) \\
4(9.8)\end{array}$ & $\begin{array}{l}- \\
\text { I }(2.4) \\
\text { I }(2.4) \\
3(7.3) \\
3(7.3)\end{array}$ \\
\hline Comprehension & Token test & $4.95 \pm 0.15$ & $4(9.8)$ & - \\
\hline Executive functions & $\begin{array}{l}\text { TMT } \mathrm{B}^{\mathrm{a}} \\
\text { Cognitive estimations } \\
\text { Abstract reasoning } \\
\text { Phonemic fluency } \\
\text { Clock drawing }\end{array}$ & $\begin{array}{l}139.85 \pm 101.76 \\
4.71 \pm 0.60 \\
5.20 \pm 1.44 \\
11.50 \pm 3.64 \\
7.72 \pm 2.64\end{array}$ & $\begin{array}{l}8(19.5) \\
1(2.4) \\
3(7.3) \\
7(17.1) \\
12(29.3)\end{array}$ & $\begin{array}{l}\text { I }(2.4) \\
9(22.0) \\
- \\
5(12.2) \\
4(9.8)\end{array}$ \\
\hline Visuospatial abilities & $\begin{array}{l}\text { Overlapping figure test } \\
\text { Copy drawing } \\
\text { Spontaneous drawing }\end{array}$ & $\begin{array}{l}30.05 \pm 8.01 \\
1.63 \pm 0.49 \\
1.80 \pm 0.51\end{array}$ & $\begin{array}{l}13(31.7) \\
15(36.6) \\
6(14.6)\end{array}$ & $\begin{array}{l}6(14.6) \\
- \\
-\end{array}$ \\
\hline Praxis abilities & Ideative and ideomotor praxis test & $5.93 \pm 0.26$ & $3(7.3)$ & - \\
\hline Global score & & $75.00 \pm 10.11$ & $13(31.7)$ & - \\
\hline
\end{tabular}

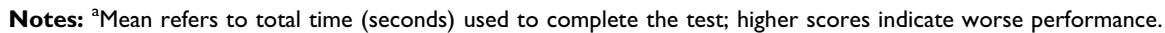

Abbreviations: SD, standard deviation; N, number; AUD, alcohol use disorder; TMT, Trail Making Test.

(visuospatial abilities) $(F=8.07 ; p<0.01)$. No significant differences were found for work status (all $p>0.05$ ).

Concerning clinical and psychological factors, the data show that: 1) abstainers at admission performed better in Prose memory - immediate $(F=7.980 ; p<0.01)$ and delayed $(F=9.101 ; p<0.01)$ recall (memory), Phonemic fluency $(F=4.829 ; p=0.03)$ (executive functions) and Overlapping figure test $(F=4.756 ; p=0.03)$ (visuospatial abilities) compared to others; 2) patients with a prolonged duration of AUD scored lower in Digit span $(F=5.798 ; p=0.02)$ (memory) in comparison with people

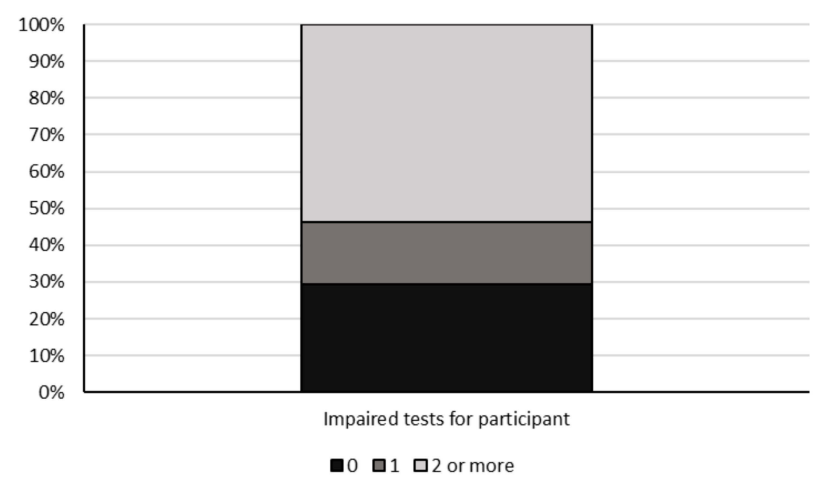

Figure I Distribution of the sample by number of impaired tests in the ENB-2. with a shorter duration of AUD; 3) people with a history of substance abuse $(F=4.964 ; p=0.03)$ and with substance abuse comorbidity at admission $(F=7.110 ; p=0.01)$ obtained worse scores in Copy drawing (visuospatial abilities) in comparison to those who did not have previous or present substance abuse; and 4) moderate or high levels of anxiety were associated with higher scores in Abstract reasoning $(F=8.930 ; p<0.01)$ (executive functions). No significant differences were found for depression, AUDIT or psychiatric diagnosis (all $p>0.05$ ).

Lastly, we compared all cognitive domains at baseline between the relapsed group and the abstinent group at followup, but no statistically significant differences were found.

\section{Discussion}

The first aim of this study was to examine neuropsychological functioning in early-detoxified AUD patients attending a 28-day residential rehabilitation program.

The results showed a considerable number of people showing cognitive deficits concerned with executive functions, visuospatial abilities and memory. These results are in line with the literature, which suggested that between $50 \%$ and $80 \%$ of alcohol-dependent patients present impaired cognitive functions. ${ }^{8}$ Galandra et al, using both 
Table 3 Psychological Assessment: Results of Self-Report Questionnaires

\begin{tabular}{|l|l|l|}
\hline Variable & & N (\%) or M (SD) \\
\hline \multirow{2}{*}{ Anxiety } & Clinically relevant $^{\mathrm{a}}$ & $19(46.3)$ \\
\cline { 2 - 3 } & Not relevant $^{\mathrm{b}}$ & $14(34.1)$ \\
\hline \multirow{2}{*}{ Depression } & Clinically relevant $^{\mathrm{a}}$ & $21(5 \mathrm{I} .2)$ \\
\cline { 2 - 3 } & Not relevant $^{\mathrm{b}}$ & $12(29.3)$ \\
\hline AUDIT & & $32.25(6.77)$ \\
\hline
\end{tabular}

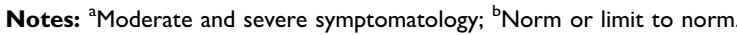
Abbreviations: N, number; $M$, mean; SD, standard deviation; AUDIT, Alcohol Use Disorders Identification Test.

voxel-based morphometry (VBM) and neuropsychological assessment, explained AUD patients' executive impairment as a defective access to attention and working memory skills, due to the structural damage of a salience-based neural mechanism correlated with the executive network. ${ }^{61}$ Deficits in executive functions may negatively affect working memory, mental flexibility, divided attention, decision-making, problem-solving and inhibition. ${ }^{8}$

Previous studies also found that performances in the visuospatial domain are largely affected in terms of visuospatial processing, memory and organization. ${ }^{9,46}$ Memory is a complex function that includes multiple components and processes, and in AUD patients is associated with short- and long-term memory deficits. ${ }^{40,42}$

These cognitive functions are fundamental for AUD patients to benefit from psychosocial treatments during recovery because CBT and motivational interventions require preserved cognitive functions to be effective. ${ }^{8,67,68}$

Our results showed that $70.73 \%$ of the total sample had impaired performance on at least one test of the

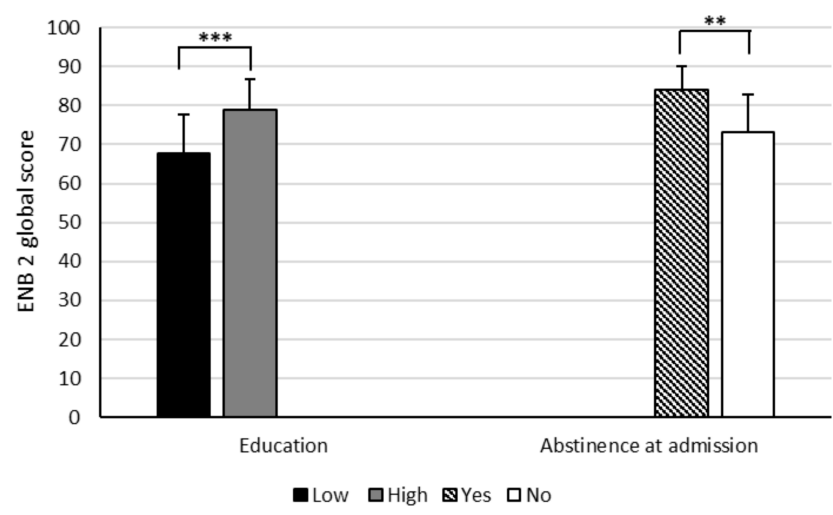

Figure 2 Comparison between mean global scores in the ENB-2 for different conditions of education and abstinence.

Notes: $* * p<0.01 ; * * * p<0.001$ neuropsychological battery items. These findings are in line with a study which found that, after completing acute detoxification, almost all participants (93\%) were clinically impaired in at least one of the five cognitive domains at entry to residential treatment and $71 \%$ remained clinically impaired after 10 days. ${ }^{68}$ This means that abstinence has a relevant role for neuropsychological functioning, but it is not the only factor since some individuals remained cognitively impaired.

It is important to use a comprehensive and standardized neuropsychological battery to assess cognitive functioning among alcohol-dependent people in order to carefully investigate impaired domains. Indeed, if we had limited ourselves to considering only the results of the cognitive global score, we would have found that the majority of patients (68.3\%) did not present a clinical score according to normative scores (adjusted for age and education). Conversely, high levels of impaired scores in tests assessing executive functions and visuospatial abilities can be considered as warning signals which suggest paying attention to AUD patients' cognitive functioning, first in terms of neuropsychological assessment and diagnosis, and then in terms of tailored interventions or clinical suggestions for discharge when necessary. ${ }^{9}$

Providing targeted individual treatments is a high-value goal, although some precautions is needed. Time of assessment is a fundamental facet: during the first week, patients may experience withdrawal symptoms, which can interfere with performance and thus test scores. In parallel, since most rehabilitation programs are usually 4 weeks long, time is key in order to furnish a tailored intervention as soon as possible. Therefore, it is necessary to obtain neuropsychological data in the early stages, always bearing in mind the adverse effects that alcohol abstinence causes in patients. Further research is needed to find the best balance between day of evaluation, partial brain recovery and the extinction of, or at least a sharp decrease in, withdrawal symptoms.

The secondary aim of this study was to explore any differences in cognitive performance in relation to the main socio-demographic, clinical and psychological factors of the alcohol-dependent population.

Previous studies suggest that approximately $50 \%$ of problem drinkers do not experience negative consequences of chronic alcohol abuse. ${ }^{12,14,69}$ This means that there is interindividual variability in the nature and severity of these impairments. In this regard, a number of factors, such as age, education, history of drinking, psychiatric conditions and length of abstinence, have been identified as correlates of cognitive functioning 
Table 4 Cognitive Functions and the Role of Socio-Demographic Factors

\begin{tabular}{|c|c|c|c|c|c|}
\hline \multirow[t]{3}{*}{ Cognitive Domain } & \multirow[t]{3}{*}{ Test } & $M(S D)$ & $M(S D)$ & \multirow[t]{3}{*}{$\mathbf{F}$} & \multirow[t]{3}{*}{$\mathbf{p}$} \\
\hline & & \multicolumn{2}{|l|}{ Gender } & & \\
\hline & & Male & Female & & \\
\hline \multirow[t]{3}{*}{ Executive functions } & \multirow[t]{3}{*}{ Abstract reasoning } & $4.79(1.74)$ & $5.77(0.43)$ & \multirow[t]{3}{*}{5.032} & \multirow[t]{3}{*}{0.03} \\
\hline & & \multicolumn{2}{|l|}{ Age (years) } & & \\
\hline & & $\leq 50$ & $\geq 51$ & & \\
\hline Attention & TMT A & $34.11(10.55)$ & $44.68(21.02)$ & 3.789 & 0.05 \\
\hline \multirow[t]{4}{*}{ Executive functions } & \multirow{4}{*}{$\begin{array}{l}\text { Phonemic fluency } \\
\text { Abstract reasoning }\end{array}$} & $12.87(3.90)$ & $10.42(3.11)$ & \multirow{4}{*}{$\begin{array}{l}4.998 \\
4.729\end{array}$} & \multirow{4}{*}{$\begin{array}{l}0.03 \\
0.03\end{array}$} \\
\hline & & $5.72(0.46)$ & $4.78(1.78)$ & & \\
\hline & & \multicolumn{2}{|c|}{ Education (years) } & & \\
\hline & & $\leq 8$ & $\geq 9$ & & \\
\hline \multirow[t]{4}{*}{ Memory } & Prose memory - immediate recall & $11.86(3.11)$ & $15.63(4.93)$ & 6.751 & 0.01 \\
\hline & Prose memory - delayed recall & $14.57(4.15)$ & $20.19(4.58)$ & 14.725 & $<0.001$ \\
\hline & Memory with interference -10 seconds & $5.71(3.24)$ & $7.63(1.86)$ & 5.807 & 0.02 \\
\hline & Memory with interference -30 seconds & $5.21(2.52)$ & $7.30(2.11)$ & 7.872 & $<0.01$ \\
\hline Executive functions & Phonemic fluency & $9.53(2.80)$ & $|2.5|(3.65)$ & 7.139 & 0.01 \\
\hline Visuospatial abilities & Copy drawing & $\mathrm{I} .36(0.50)$ & $1.78(0.42)$ & 8.072 & $<0.01$ \\
\hline
\end{tabular}

Notes: ${ }^{a}$ Mean refers to total time (seconds) used to complete the test; higher scores indicate worse performance.

Abbreviations: M, mean; SD, standard deviation; TMT, Trail Making Test.

and brain recovery, but the results are mixed and more research is needed. The results of this study showed that with regard to socio-demographic factors, patients with low education performed worse in tests assessing memory, executive functions and visuospatial abilities compared to the group with high education, while older adults scored lower in tasks related to attention and executive functions compared to younger ones. ${ }^{50,51}$ The early detection of alcohol-related cognitive impairment in older people with AUD can improve social outcomes in both drinking behavior and the social consequences of alcohol-related dementia. ${ }^{70}$ Woods et al found that heavy alcohol consumption was associated with greater cognitive impairment in older adults. ${ }^{14}$ Furthermore, Pitel et al found that the younger the abstainers were when they quit drinking, the better the executive recovery. ${ }^{12}$

In relation to clinical factors, we found a key role played by length of abstinence, since abstinent patients at admission had better performance in memory, executive functions and visuospatial abilities compared to other patients. Abstinence seems to significantly affect cognitive recovery, even if some deficits often persist in the long term. ${ }^{54,71}$
Pitel et al found that episodic memory recovery was correlated with drinking history; analogously, we found that patients with a shorter duration of dependence scored better in the Digit Span test compared to those with more than 10 years of alcohol dependence. ${ }^{12}$

In addition, our data found that polysubstance abusers at admission performed significantly worse than pure alcoholics in the Copy drawing test, contrary to the findings of Beatty et al, although their subjects were tested after a longer period of abstinence. ${ }^{72}$ Also, the group with a history of drug abuse scored worse in the same test compared to pure alcoholics, suggesting that drug abuse may worsen visuospatial deficits, in accordance with the findings of Selby and Azrin. ${ }^{52,73}$

Concerning psychological factors, the presence or absence of a psychiatric diagnosis and level of depression did not show significant differences in any cognitive performances, whereas higher levels of anxiety were paired with better scores in the Abstract reasoning test. The relationship between state anxiety and executive functions is controversial since previous studies have reported both positive and negative associations using tests evaluating these domains in different populations. ${ }^{74-76}$ 
Table 5 Cognitive Functions and the Role of Clinical and Psychological Factors

\begin{tabular}{|c|c|c|c|c|c|}
\hline \multirow[t]{3}{*}{ Cognitive Domain } & \multirow[t]{3}{*}{ Test } & $M(S D)$ & $M(S D)$ & \multirow[t]{3}{*}{$\mathbf{F}$} & \multirow[t]{3}{*}{$\mathbf{p}$} \\
\hline & & \multicolumn{2}{|c|}{ Abstinence at Admission } & & \\
\hline & & Yes & No & & \\
\hline \multirow[t]{2}{*}{ Memory } & Prose memory - immediate recall & $18.57(3.78)$ & $13.47(4.45)$ & 7.980 & $<0.01$ \\
\hline & Prose memory - delayed recall & $23.14(4.67)$ & $17.26(4.70)$ & 9.101 & $<0.01$ \\
\hline Executive functions & Phonemic fluency & $14.13(3.32)$ & $10.95(3.5 \mathrm{I})$ & 4.829 & 0.03 \\
\hline \multirow[t]{3}{*}{ Visuospatial abilities } & \multirow[t]{3}{*}{ Overlapping figure test } & $35.85(7.62)$ & $28.85(7.76)$ & \multirow[t]{3}{*}{4.756} & \multirow[t]{3}{*}{0.03} \\
\hline & & \multicolumn{2}{|c|}{ Duration of AUD (years) } & & \\
\hline & & $2-9$ & $\geq 10$ & & \\
\hline \multirow[t]{3}{*}{ Memory } & \multirow[t]{3}{*}{ Digit span } & $6.00(1.08)$ & $5.30(0.76)$ & \multirow[t]{3}{*}{5.798} & \multirow[t]{3}{*}{0.02} \\
\hline & & \multicolumn{2}{|c|}{ Substance use comorbidity } & & \\
\hline & & Yes & No & & \\
\hline \multirow[t]{3}{*}{ Visuospatial abilities } & \multirow[t]{3}{*}{ Copy drawing } & $1.25(0.46)$ & $1.73(0.45)$ & \multirow[t]{3}{*}{7.110} & \multirow[t]{3}{*}{0.01} \\
\hline & & \multicolumn{2}{|c|}{ Previous substance abuse } & & \\
\hline & & Yes & No & & \\
\hline \multirow[t]{3}{*}{ Visuospatial abilities } & \multirow[t]{3}{*}{ Copy drawing } & $\mathrm{I} .48(0.5 \mathrm{I})$ & $\mathrm{I} .80(0.4 \mathrm{I})$ & \multirow[t]{3}{*}{4.964} & \multirow[t]{3}{*}{0.03} \\
\hline & & \multicolumn{2}{|l|}{ Anxiety } & & \\
\hline & & Norm & Moderate/high levels & & \\
\hline Executive functions & Abstract reasoning & $4.21(2.04)$ & $5.68(0.58)$ & 8.930 & $<0.01$ \\
\hline
\end{tabular}

Abbreviations: $M$, mean; SD, standard deviation; AUD, alcohol use disorder.

Finally, there was no significant difference regarding neuropsychological scores at baseline between abstainers and relapsers at 1-month follow-up. Previous studies have explored the relationship between cognitive impairment and relapses, with conflicting results. ${ }^{9,12}$ After discharge, the early-detoxified abstainer is no longer in a safe environment, where staff and other patients head toward the same goal, but faces daily life, where abstinence is tougher to maintain. Cognitive functioning certainly has a role, especially higher domains such as executive functions, but relapse is a complex and dynamic event that is determined by biological, psychological and societal factors and interactions among these. ${ }^{77}$ However, research in this context should also focus on the role of neuropsychological factors since the majority of studies did not include them in their predictive models. ${ }^{78}$

Some limitations of this study should be mentioned. First, although several studies in this specific clinical population used similar numbers, the sample size is quite small and only limited quantitative analyses were performed since the main focus was to describe qualitatively the cognitive deficits in patients undergoing treatment for AUD. ${ }^{12,13,68,79}$ However, this represents an exploratory study and further research are needed to increase the validity of the results. Second, this study is cross-sectional, with a single neuropsychological assessment of early-detoxified patients; it would be useful to use a longitudinal perspective in order to study cognitive changes over time after detoxification. However, we used a standardized and comprehensive neuropsychological battery exploring multiple domains, such as the ENB-2, to obtain a bigger picture of the cognitive status of the patient.

\section{Conclusion}

The results of this study underlined that a neuropsychological assessment should be considered as an important aspect of a rehabilitation program for alcohol-dependent people. The detection of cognitive impairments is therefore essential and should be systematic, using a comprehensive and standardized neuropsychological screening battery. ${ }^{8}$ Most AUD 
patients showed deficits in executive functions, visuospatial abilities and memory that may impede the effectiveness of psychosocial treatments. Indeed, cognitively impaired patients may have limited capacity to benefit fully from the treatment and to maintain abstinence. ${ }^{9}$ Furthermore, specific attention should be paid to some factors that may be associated with cognitive impairments, such as age, education, duration of abstinence, polysubstance abuse and history of substance abuse use disorder.

Alcohol rehabilitation treatment should therefore be adapted to patients with cognitive impairments in order to reduce the recycling of patients through the treatment centers and prevent patients from going through repeated detoxifications.

\section{Disclosure}

The authors report no conflicts of interest in this work.

\section{References}

1. World Health Organization. Global Status Report on Alcohol and Health: 2014. Luxembourg: WHO; 2014.

2. American Psychiatric Association. Diagnostic and Statistical Manual of Mental Disorders $\left(D S M-5^{\circledR}\right)$. 2. Washington, DC: American Psychiatric Publishing; 2013.

3. World Health Organization. Global Status Report on Alcohol and Health 2018. 3. Geneva: Switzerland: WHO; 2019.

4. Darvishi N, Farhadi M, Haghtalab T, Poorolajal J, Voracek M. Alcohol-related risk of suicidal ideation, suicide attempt, and completed suicide: a meta-analysis. PLoS One. 2015;10(5):e0126870. doi:10.1371/journal.pone. 0126870

5. Ronksley PE, Brien SE, Turner BJ, Mukamal KJ, Ghali WA. Association of alcohol consumption with selected cardiovascular disease outcomes: a systematic review and meta-analysis. $B M J$. 2011;342(feb22 1):d671. doi:10.1136/bmj.d671

6. Testino G. Alcoholic diseases in hepato-gastroenterology: a point of view. Hepatogastroenterology. 2008;55(82-83):371-377.

7. National Institute on Alcohol Abuse and Alcoholism (NIAAA). Health risks and benefits of alcohol consumption. Alcohol Res Health. 2000;24(1):5-11.

8. Bernardin F, Maheut-Bosser A, Paille F. Cognitive impairments in alcohol-dependent subjects. Front Psychiatry. 2014;5:78. doi:10.3389/fpsyt.2014.00078

9. Le Berre AP, Laniepce A, Segobin S, Pitel AL, Sullivan EV. Alcohol use disorder: permanent and transient effects on the brain and neuropsychological functions. In: Stern RA, Alosco ML, editors. The Oxford Handbook of Adult Cognitive Disorders. Oxford, UK: Oxford University Press; 2019:302-332.

10. Ryback RS. The continuum and specificity of the effects of alcohol on memory; a review. $Q J$ Stud Alcohol. 1971;32(4):995-1016. doi:10.15288/qjsa.1971.32.995

11. Beatty WW, Tivis R, Stott HD, Nixon SJ, Parsons OA. Neuropsychological deficits in sober alcoholics: influences of chronicity and recent alcohol consumption. Alcohol Clin Exp Res. 2000;24 (2):149-154. doi:10.1111/j.1530-0277.2000.tb04584.x

12. Pitel AL, Rivier J, Beaunieux H, Vabret F, Desgranges B, Eustache F. Changes in the episodic memory and executive functions of abstinent and relapsed alcoholics over a 6-month period. Alcohol Clin Exp Res. 2009;33(3):490-498. doi:10.1111/j.1530-0277.2008.00859.x
13. Green A, Garrick T, Sheedy D, Blake H, Shores EA, Harper C. The effect of moderate to heavy alcohol consumption on neuropsychological performance as measured by the repeatable battery for the assessment of neuropsychological status. Alcohol Clin Exp Res. 2010;34(3):443-450. doi:10.1111/j.1530-0277.2009.01108.x

14. Woods AJ, Porges EC, Bryant VE, et al. Current heavy alcohol consumption is associated with greater cognitive impairment in older adults. Alcohol Clin Exp Res. 2016;40(11):2435-2444. doi:10.1111/acer.13211

15. Duka T, Townshend JM, Collier K, Stephens DN. Impairment in cognitive functions after multiple detoxifications in alcoholic inpatients. Alcohol Clin Exp Res. 2003;27(10):1563-1572. doi:10.1097/01.ALC.0000090142.11260.D7

16. Ritz L, Coulbault L, Lannuzel C, et al. Clinical and biological risk factors for neuropsychological impairment in alcohol use disorder. PLoS One. 2016;11(9):e0159616. doi:10.1371/journal.pone.0159616

17. Lusins J, Zimberg S, Smokier H, Gurley K. Alcoholism and cerebral atrophy: a study of 50 patients with CT scan and psychologic testing. Alcohol Clin Exp Res. 1980;4(4):406-411. doi:10.1111/j.15300277.1980.tb04840.x

18. Pfefferbaum A, Sullivan EV, Mathalon DH, Shear PK, Rosenbloom MJ, Lim KO. Longitudinal changes in magnetic resonance imaging brain volumes in abstinent and relapsed alcoholics. Alcohol Clin Exp Res. 1995;19(5):1177-1191. doi:10.1111/j.15300277.1995.tb01598.x

19. Oscar-Berman M, Marinkovic K. Alcoholism and the brain: an overview. Alcohol Res Health. 2003;27(2):125-133.

20. Mechtcheriakov S, Brenneis C, Egger K, Koppelstaetter F, Schocke M, Marksteiner J. A widespread distinct pattern of cerebral atrophy in patients with alcohol addiction revealed by voxel-based morphometry. J Neurol Neurosurg Psychiatry. 2007;78(6):610-614. doi:10.1136/jnnp.2006.095869

21. Monnig MA, Tonigan JS, Yeo RA, Thoma RJ, McCrady BS. White matter volume in alcohol use disorders: a meta-analysis. Addict Biol. 2013;18(3):581-592. doi:10.1111/j.1369-1600.2012.00441.x

22. Ron MA. The alcoholic brain: CT scan and psychological findings. Psychol Med Monogr Suppl. 1983;3:1-33. doi:10.1017/S0264 180100000345

23. Chanraud S, Martelli C, Delain F, et al. Brain morphometry and cognitive performance in detoxified alcohol-dependents with preserved psychosocial functioning. Neuropsychopharmacology. 2007;32(2):429-438. doi:10.1038/sj.npp.1301219

24. Davies SJC, Pandit SA, Feeney A, et al. Is there cognitive impairment in clinically 'healthy' abstinent alcohol dependence? Alcohol Alcohol. 2005;40(6):498-503. doi:10.1093/alcalc/agh203

25. Sullivan EV, Rosenbloom MJ, Pfefferbaum A. Pattern of motor and cognitive deficits in detoxified alcoholic men. Alcohol Clin Exp Res. 2000;24(5):611-621. doi:10.1111/j.1530-0277.2000.tb02032.x

26. Sullivan EV, Fama R, Rosenbloom MJ, Pfefferbaum A. A profile of neuropsychological deficits in alcoholic women. Neuropsychology. 2002;16(1):74-83. doi:10.1037/0894-4105.16.1.74

27. Fama R, Pfefferbaum A, Sullivan EV. Perceptual learning in detoxified alcoholic men: contributions from explicit memory, executive function, and age. Alcohol Clin Exp Res. 2004;28(11):1657-1665. doi:10.1097/01.ALC.0000145690.48510.DA

28. Fein G, Landman B, Tran H, et al. Brain atrophy in long-term abstinent alcoholics who demonstrate impairment on a simulated gambling task. Neuroimage. 2006;32(3):1465-1471. doi:10.1016/j. neuroimage.2006.06.013

29. Goldstein RZ, Leskovjan AC, Hoff AL, et al. Severity of neuropsychological impairment in cocaine and alcohol addiction: association with metabolism in the prefrontal cortex. Neuropsychologia. 2004;42 (11):1447-1458. doi:10.1016/j.neuropsychologia.2004.04.002

30. Brion M, D'Hondt F, Pitel A, et al. Executive functions in alcohol-dependence: a theoretically grounded and integrative exploration. Drug Alcohol Depend. 2017;177:39-47. doi:10.1016/j. drugalcdep.2017.03.018 
31. Noël X, Bechara A, Brevers D, Verbanck P, Campanella S. Alcoholism and the loss of willpower: a neurocognitive perspective. J Psychophysiol. 2010;24(4):240-248. doi:10.1027/0269-8803/a000037

32. Camchong J, Endres M, Fein G. Decision making, risky behavior, and alcoholism. In: Sullivan E, Pfefferbaum A, editors. Handbook of Clinical Neurology. Elsevier; 2014:227-236.

33. O'Leary MR, Radford LM, Chaney EF, Schau EJ. Assessment of cognitive recovery in alcoholics by use of the trail-making test. J Clin Psychol. 1977;33(2):579-582. doi:10.1002/1097-4679(197704) 33:2<579::AID-JCLP2270330254>3.0.CO;2-R

34. Fein G, Torres J, Price LJ, Di Sclafani V. Cognitive performance in long-term abstinent alcoholic individuals. Alcohol Clin Exp Res. 2006;30(9):1538-1544. doi:10.1111/j.1530-0277.2006.00185.x

35. Munro CA, Saxton J, Butters MA. The neuropsychological consequences of abstinence among older alcoholics: a cross-sectional study. Alcohol Clin Exp Res. 2000;24(10):1510-1516. doi:10.1111/ j.1530-0277.2000.tb04569.x

36. Tedstone D, Coyle K. Cognitive impairments in sober alcoholics: performance on selective and divided attention tasks. Drug Alcohol Depend. 2004;75(3):277-286. doi:10.1016/j.drugalcdep.2004.03.005

37. Beatty WW, Katzung VM, Moreland VJ, Nixon SJ. Neuropsychological performance of recently abstinent alcoholics and cocaine abusers. Drug Alcohol Depend. 1995;37(3):247-253. doi:10.1016/0376-8716(94)01072-S

38. Noël X, Van der Linden M, Schmidt N, et al. Supervisory attentional system in nonamnesic alcoholic men. Arch Gen Psychiatry. 2001;58 (12):1152-1158. doi:10.1001/archpsyc.58.12.1152

39. Zinn S, Stein R, Swartzwelder HS. Executive functioning early in abstinence from alcohol. Alcohol Clin Exp Res. 2004;28 (9):1338-1346. doi:10.1097/01.ALC.0000139814.81811.62

40. Pitel AL, Beaunieux H, Witkowski T, et al. Genuine episodic memory deficits and executive dysfunctions in alcoholic subjects early in abstinence. Alcohol Clin Exp Res. 2007;31(7):1169-1178. doi:10.1111/j.1530-0277.2007.00418.x

41. Chanraud S, Leroy C, Martelli C, et al. Episodic memory in detoxified alcoholics: contribution of grey matter microstructure alteration. PLoS One. 2009;4(8):e6786. doi:10.1371/journal.pone.0006786

42. Noël X, Van der Linden M, Brevers D, et al. The contribution of executive functions deficits to impaired episodic memory in individuals with alcoholism. Psychiatry Res. 2012;198(1):116-122. doi:10.1016/j.psychres.2011.10.007

43. Sullivan EV, Mathalon DH, Ha CN, Zipursky RB, Pfefferbaum A. The contribution of constructional accuracy and organizational strategy to nonverbal recall in schizophrenia and chronic alcoholism. Biol Psychiatry. 1992;32(4):312-333. doi:10.1016/0006-3223(92)90036-Y

44. Chen J, Qian M, Sun C, Lin M, Tang W. Clinical effectiveness of cognitive behavioural therapy on alcohol-dependent patients: an observation with the WeChat platform. Gen Psychiatr. 2019;32(5): e100087. doi:10.1136/gpsych-2019-100087

45. Magill M, Ray L, Kiluk B, et al. A meta-analysis of cognitive-behavioral therapy for alcohol or other drug use disorders: treatment efficacy by contrast condition. J Consult Clin Psychol. 2019;87(12):1093-1105. doi:10.1037/ccp0000447

46. Alarcon R, Nalpas B, Pelletier S, Perney P. MoCA as a screening tool of neuropsychological deficits in alcohol- dependent patients. Alcohol Clin Exp Res. 2015;39(6):1042-1048. doi:10.1111/acer.12734

47. Fein G, Bachman L, Fisher S, Davenport L. Cognitive impairments in abstinent alcoholics. West J Med. 1990;152(5):531-537.

48. Rourke SB, Grant I. The interactive effects of age and length of abstinence on the recovery of neuropsychological functioning in chronic male alcoholics: a 2-year follow-up study. J Int Neuropsychol Soc. 1999;5(3):234-246. doi:10.1017/S13556 17799533067

49. Manning V, Wanigaratne S, Best D, et al. Changes in neuropsychological functioning during alcohol detoxification. Eur Addict Res. 2008;14(4):226-233. doi:10.1159/000156479
50. Nunes PT, Kipp BT, Reitz NL, Savage LM. Aging with alcohol-related brain damage: critical brain circuits associated with cognitive dysfunction. Int Rev Neurobiol. 2019;148:101-168.

51. Sullivan EV, Pfefferbaum A. Brain-behavior relations and effects of aging and common comorbidities in alcohol use disorder: a review. Neuropsychology. 2019;33(6):760-780. doi:10.1037/ neu0000557

52. Fernandez-Serrano MJ, Pérez-García M, Schmidt Río-Valle J, Verdejo-Garcia A. Neuropsychological consequences of alcohol and drug abuse on different components of executive functions. J Psychopharmacol. 2010;24(9):1317-1332. doi:10.1177/ 0269881109349841

53. Bartels C, Kunert HJ, Stawicki S, Kröner-Herwig B, Ehrenreich H, Krampe H. Recovery of hippocampus-related functions in chronic alcoholics during monitored long-term abstinence. Alcohol Alcohol. 2007;42(2):92-102. doi:10.1093/alcalc/agl104

54. Kaur P, Sidana A, Malhotra N, Gupta A. Effects of abstinence of alcohol on neurocognitive functioning in patients with alcohol dependence syndrome. Asian J Psychiatr. 2020;50:101997. doi:10.1016/j. ajp.2020.101997

55. Lookatch SJ, Elledge LC, Anderson S, Shorey RC, Stuart GL, Moore TM. Cognitive and psychological changes during 28-day residential substance use treatment. Addict Res Theory. 2017;25 (4):334-341. doi:10.1080/16066359.2017.1281408

56. Morrison F. Neuropsychological impairment and relapse following inpatient detoxification in severe alcohol dependence. Int $J$ Ment Health Addict. 2011;9(2):151-161. doi:10.1007/ s11469-009-9261-x

57. Fiabane E, Ottonello M, Zavan V, Pistarini C, Giorgi I. Motivation to change and posttreatment temptation to drink: a multicenter study among alcohol-dependent patients. Neuropsychiatr Dis Treat. 2017;13:2497-2504. doi:10.2147/NDT.S137766

58. Giorgi I, Ottonello M, Vittadini G, Bertolotti G. Psychological changes in alcohol-dependent patients during a residential rehabilitation program. Neuropsychiatr Dis Treat. 2015;11:2989-2996. doi:10.2147/NDT.S93520

59. Ottonello M, Fiabane E, Pistarini C, Spigno P, Torselli E. Difficulties in emotion regulation during rehabilitation for alcohol addiction: correlations with metacognitive beliefs about alcohol use and relapse risk. Neuropsychiatr Dis Treat. 2019;15:2917-2925. doi:10.2147/ NDT.S214268

60. Mondini S, Mapelli D, Vestri A, Arcara G, Bisiacchi PS. L'Esame Neuropsicologico Breve-2 (Brief Neuropsychological Examination2). Milano, Italy: Raffaello Cortina Editore; 2011.

61. Galandra C, Basso G, Manera M, et al. Salience network structural integrity predicts executive impairment in alcohol use disorders. Sci Rep. 2018;8(1):1-13. doi:10.1038/s41598-018-32828-x

62. Mondini S. Esame neuropsicologico breve: Una batteria di test per lo screening neuropsicologico. Milano, Italy: Raffaello Cortina Editore; 2003.

63. Parolin M, Simonelli A, Mapelli D, Sacco M, Cristofalo P. Parental substance abuse as an early traumatic event. Preliminary findings on neuropsychological and personality functioning in young drug addicts exposed to drugs early. Front Psychol. 2016;7:887. doi:10.3389/fpsyg.2016.00887

64. Bertolotti G, Michielin P, Vidotto G, et al. Metric qualities of the cognitive behavioral assessment for outcome evaluation to estimate psychological treatment effects. Neuropsychiatr Dis Treat. 2015;11:2449-2460. doi:10.2147/NDT.S86855

65. Babor TF, Ramon de la Fuente J, Saunders J, et al. AUDIT: The Alcohol Use Disorders Test: Guidelines for Use in Primary Care. Geneva: World Health Organisation (WHO); 1992.

66. Fukuoka Y, Dracup K, Takeshima M, et al. Effect of job strain and depressive symptoms upon returning to work after acute coronary syndrome. Soc Sci Med. 2009;68(10):1875-1881. doi:10.1016/j. socscimed.2009.02.030 
67. Domínguez-Salas S, Díaz-Batanero C, Lozano-Rojas OM, VerdejoGarcía A. Impact of general cognition and executive function deficits on addiction treatment outcomes: systematic review and discussion of neurocognitive pathways. Neurosci Biobehav Rev. 2016;71:772-801. doi:10.1016/j.neubiorev.2016.09.030

68. Mulhauser K, Weinstock J, Ruppert P, Benware J. Changes in neuropsychological status during the initial phase of abstinence in alcohol use disorder: neurocognitive impairment and implications for clinical care. Subst Use Misuse. 2018;53(6):881-890. doi:10.1080/ 10826084.2017.1408328

69. Oscar-Berman M, Marinkovic K. Alcohol: effects on neurobehavioral functions and the brain. Neuropsychol Rev. 2007;17(3):239-257. doi:10.1007/s11065-007-9038-6

70. Rao R. Cognitive impairment in older people with alcohol use disorders in a UK community mental health service. Adv Dual Diagn. 2016;9(4):154-158. doi:10.1108/ADD-06-2016-0014

71. Stavro K, Pelletier J, Potvin S. Widespread and sustained cognitive deficits in alcoholism: a meta-analysis. Addict Biol. 2013;18 (2):203-213. doi:10.1111/j.1369-1600.2011.00418.x

72. Beatty WW, Blanco CR, Hames KA, Nixon SJ. Spatial cognition in alcoholics: influence of concurrent abuse of other drugs. Drug Alcohol Depend. 1997;44(2-3):167-174. doi:10.1016/S03768716(97)01334-3

73. Selby MJ, Azrin RL. Neuropsychological functioning in drug abusers. Drug Alcohol Depend. 1998;50(1):39-45. doi:10.1016/ S0376-8716(98)00002-7
74. Ursache A, Raver CC. Trait and state anxiety: relations to executive functioning in an at-risk sample. Cogn Emot. 2014;28(5):845-855. doi:10.1080/02699931.2013.855173

75. Visu-Petra L, Miclea M, Visu-Petra G. Individual differences in anxiety and executive functioning: a multidimensional view. Int J Psychol. 2013;48(4):649-659. doi:10.1080/00207594.2012. 656132

76. Kofman O, Meiran N, Greenberg E, Balas M, Cohen H. Enhanced performance on executive functions associated with examination stress: evidence from task-switching and Stroop paradigms. Cogn Emot. 2006;20(5):577-595. doi:10.1080/02699930500270913

77. Martino F, Caselli G, Fiabane E, et al. Desire thinking as a predictor of drinking status following treatment for alcohol use disorder: a prospective study. Addict Behav. 2019;95:70-76. doi:10.1016/j. addbeh.2019.03.004

78. Fiabane E, Scotti L, Zambon A, Vittadini G, Giorgi I. Frequency and predictors of treatment outcomes following alcohol residential rehabilitation program: a 12-month follow-up study. Int $J$ Environ Res Public Health. 2019;16(5):722. doi:10.3390/ijerph16050722

79. Torselli E, Ottonello M, Franceschina E, Palagi E, Bertolotti G, Fiabane E. Cognitive and metacognitive factors among alcohol-dependent patients during a residential rehabilitation program: a pilot study. Neuropsychiatr Dis Treat. 2018;14:1907-1917. doi:10.2147/NDT.S166669

\section{Publish your work in this journal}

Neuropsychiatric Disease and Treatment is an international, peerreviewed journal of clinical therapeutics and pharmacology focusing on concise rapid reporting of clinical or pre-clinical studies on a range of neuropsychiatric and neurological disorders. This journal is indexed on PubMed Central, the 'PsycINFO' database and CAS, and is the official journal of The International Neuropsychiatric Association (INA). The manuscript management system is completely online and includes a very quick and fair peer-review system, which is all easy to use. Visit http://www.dovepress.com/testimonials.php to read real quotes from published authors. 